\title{
Ribulose-1,5-bisphosphate carboxylase as a sustainable and promising plant source of bioactive peptides for food applications
}

\author{
Chibuike C. Udenigwe ${ }^{1, *}$ \\ Chigozie L. Okolie ${ }^{2}$ \\ Huifang Qian ${ }^{2}$ \\ Ikenna C. Ohanenye ${ }^{3}$ \\ Dominic Agyei ${ }^{4}$ \\ Rotimi E. Aluko 5
}

${ }^{1}$ School of Nutrition Sciences, Faculty of Health Sciences, University of Ottawa, Ottawa, Ontario, K1N 5E3, Canada

${ }^{2}$ Department of Plant, Food, and Environmental Sciences, Faculty of Agriculture, Dalhousie University, Truro, NS, B2N 5E3, Canada

${ }^{3}$ School of Water, Energy and Environment, Cranfield University, Cranfield, Bedfordshire, MK43 0AL, United Kingdom

${ }^{4}$ Department of Food Science, University of Otago, Dunedin 9054, New Zealand

${ }^{5}$ Department of Human Nutritional Sciences, Faculty of Agricultural and Food Sciences, University of Manitoba, Winnipeg, Manitoba, R3T 2N2, Canada

\author{
*Corresponding author \\ Chibuike Udenigwe, Ph.D. \\ School of Nutrition Sciences, 25 University Private \\ University of Ottawa, Ottawa, Ontario, K1N 5E3, Canada \\ E-mail cudenigw@uottawa.ca
}

Phone +1 (613) 562-5800 ext. 6539 


\begin{abstract}
Background: Plant proteins are well-known precursors of bioactive peptides. In translating the peptides into functional foods, the protein sources need to be sustainable and readily available. Ribulose-1,5-bisphosphate carboxylase/oxygenase (RuBisCO) is the major enzyme in photosynthesis and photorespiration in plants and some other organisms, and is known to be the most abundant protein on earth. Therefore, $\mathrm{RuBisCO}$ is an attractive and sustainable source of bioactive peptides.
\end{abstract}

Scope and approach: This review discusses the structure, function, composition and technology for plant RuBisCO extraction, as well as the fractionation and known bioactivities of its enzymatic hydrolysate and peptides. Feasibility of industrial scale up and practical application of the RuBisCO peptides in food were also considered. Key findings and conclusions: Several processes are available for extraction of the RuBisCO subunits and some are simple, fast and adaptable for industrial scale production. Work is however needed on recovery of high protein yields with high purity. Most studies reported that peptides, mostly from the large subunit, from enzymatic hydrolysis of spinach or alfalfa RuBisCO possess antihypertensive, opioid-like, secretagogue and food intake stimulating, antioxidant and antimicrobial activities. These properties demonstrate that RuBisCO can be utilized as a sustainable source of peptides with multiple bioactivities for formulation of functional foods.

Keywords: RuBisCO, Peptides; Antihypertensive; Antioxidant; Opioid activity; Antidiabetic; Antimicrobial peptide 


\section{Introduction}

The quest for natural and health-promoting compounds has led to increased exploration of food materials as sources of functional ingredients. Several studies in recent years have highlighted the health sustaining properties of food-derived prebiotic oligosaccharides, bioactive peptides, lipids and phytochemicals (Ale, Mikkelsen, \& Meyer, 2011; McClements, Decker, \& Park, 2009; Udenigwe \& Aluko, 2012; Maestri, Marmiroli, \& Marmiroli, 2016; Rizzello et al., 2016). Notably, bioactive proteins and peptides are emerging at the forefront of functional food trends and potentially marketable bioactive products. In general, sales of peptide-based drugs were valued at about $\$ 20$ billion and account for about $2 \%$ in annual sales of the global drug market (Sun, 2013). Such peptides are typically produced by bottom-up rational design and chemical synthesis or through heterologous expression and secretion in microbial systems. On the other hand, a top-down approach often applied in food research involves using proteins of plants, marine or animal origins as precursors of bioactive peptides (Korhonen \& Pihlanto, 2006; Ejike et al., 2017; Korhonen, Pihlanto-Leppäla, Rantamäki, \& Tuomo, 1998; Korhonen \& Pihlanto, 2003; Maestri et al., 2016). Based on this approach, proteins from milk, fish, meat and egg are commonly used as animal sources of bioactive peptides, whereas cereals, oilseeds, legumes and vegetable proteins are the popular plant-based sources. Notably, these sources of bioactive peptides are also primary dietary protein sources in different populations of the world.

Bioactive peptides are inactive within their parent protein structures until they are released by the action of endogenous or exogenous proteolytic enzymes, or by microbial fermentation (Udenigwe \& Aluko, 2012; Maestri et al., 2016; Rizzello et al., 2016). The peptides possess disease preventive and health management properties that include antihypertensive (Martínez-Maqueda, Miralles, Recio, \& Hernández-Ledesma, 2012) antidiabetic (Nongonierma \& FitzGerald, 2016), antioxidative (Samaranayaka \& Li-Chan, 2011), anticancer (Rajendran, Ejike, Gong, Hannah, \& Udenigwe, 2017), opioid-like (Teschemacher, 2003), anti-inflammatory (Chakrabarti, Jahandideh, \& Wu, 2014), hypolipidemic (Howard \& Udenigwe, 2013) and antimicrobial activities (Haque \& Chand, 2008). There has been a slow progress in the 
translation of laboratory results on bioactive peptides into commercial functional food products. Industrial-scale production of the peptides is expected to increase especially with the availability of new and emerging processing technologies. Despite the progress, some factors are perceived as impediments to the translation of bioactive peptides into functional foods. These limitations include bitterness of some peptides, food matrix-peptide interactions, low peptide bioavailability, limited human studies, lack of a consensus on their molecular mechanisms, low peptide yields, and sustainability of their protein sources (Udenigwe, 2014; Li-Chan, 2015). Sustainability becomes very important since the use of food proteins for bioactive peptides production can lead to competition with human food resources with negative impact on food security, especially in developing countries. This paper addresses the latter by discussing efforts on the exploration of widely available natural proteins as precursors for bioactive peptides.

Ribulose-1,5-bisphosphate carboxylase/oxygenase (RuBisCO) is a bifunctional multimeric plant metabolic enzyme that participates in carbon fixation in the Calvin cycle and photorespiration, depending on its affinity for carbon dioxide or molecular oxygen (Barbeau \& Kinsella, 1988). The enzyme constitutes about $50 \%$ of soluble proteins in the plant leaf and is identified as the most abundant protein on earth (Andersson \& Backlund, 2008). Despite its abundance in nature, $\mathrm{RuBisCO}$ remains underutilized as a protein in industrial food formulations (Kobbi et al., 2017), even after its functionalities and prospective food applications were highlighted three decades ago (Barbeau \& Kinsella, 1988). This slow progress is likely due to technological challenges associated with plant RuBisCO extraction or their low yield on a leaf weight basis, since $90 \%$ of green leaf is water. Emerging trend is now looking into converting non-edible and food waste vegetables into soluble protein isolates for food applications. These proteins are expected to be comprised mostly of RuBisCO. Apart from direct utilization as dietary source of amino acids in food products, one notable application explored for RuBisCO is its use as a sustainable source of bioactive peptides. As discussed later in this paper, RuBisCO-derived peptides have demonstrated beneficial effects for health promotion in vitro, in cultured cells and animal models. Moreover, bioinformatics has revealed several untapped 
peptides, most of which can be released from the large and small RuBisCO subunits by specific enzymatic proteolysis. These unexplored peptides can play several biological roles for the prevention and management of cardiovascular diseases, diabetes, immune and neurodegenerative diseases. The objective of this review is to discuss the structure, function, composition and technology for plant RuBisCO extraction as well as the fractionation and known bioactivities of its enzymatic hydrolysate and peptides for use in various food and health applications.

\section{Structure and function of RuBisCO}

RuBisCO is a major enzyme that catalyzes the first step of carbon dioxide fixation in net photosynthesis and carbon oxidation during photorespiration. Its primary role is the conversion of carbon dioxide from the biosphere into organic compounds in the rate-limiting step of the Calvin cycle (Spreitzer \& Salvucci, 2002). This is achieved through the carboxylation of ribulose-1,5-bisphosphate to produce two molecules of 3-phosphoglycerate (Andersson \& Backlund, 2008). The affinity of RuBisCO for carbon dioxide favours its carbon fixation catalytic activity. However, this is impeded by its affinity for molecular oxygen resulting in photorespiration. This process slows down the catalytic activity of carbon dioxide fixation and decreases the activity by $50 \%$; thus, RuBisCO is often referred to as an inefficient enzyme (Andersson \& Backlund, 2008; Spreitzer \& Salvucci, 2002). Consequently, photosynthetic organisms produce RuBisCO in large amounts in order to meet their metabolic needs, and it is estimated to make up over $50 \%$ of the total amounts of soluble proteins in the plant leaf (Spreitzer \& Salvucci, 2002).

RuBisCO is a large multimeric protein with a molecular weight of $560 \mathrm{kDa}$ and is found in all photosynthetic, chlorophyll-containing organisms including higher plants, green and blue-green algae, chemolithotrophic bacteria, green sulphur and purple non-sulphur bacteria (Barbeau \& Kinsella, 1988; Kobbi et al., 2017). Form I holoenzymes are the most common form of RuBisCO found in land plants and green algae (Andersson \& Backlund, 2008; Spreitzer \& Salvucci, 2002). They possess a hexadecameric structure consisting of eight large and eight 
small subunits, L8S8, which exhibit 422 local symmetry (Andersson \& Backlund, 2008). Form II RuBisCO proteins are dimeric, possess two large subunits and lack the small subunits. They are found in some prokaryotes and dinoflagellates including purple non-sulphur and chemoautotrophic bacteria (Andersson \& Backlund, 2008; Morse, Salois, Markovic, \& Hastings, 1995; Tabita, 1999; Whitney \& Andrews, 1998). On the other hand, RuBisCO in archaebacteria consists of a decamer with five large subunit dimers (Maeda et al., 1999).

\section{Chemical composition and physicochemical properties of RuBisCO}

The composition and sequence of large RuBisCO subunits from different plants are highly conserved, whereas there are notable differences in the small subunits. RuBisCO derived from spinach (Spinacia oleracea) and alfalfa (Medigaco sativa) have particularly been used to produce bioactive peptides and hydrolysates. The structure of spinach RuBisCO showing the large and small subunits is provided in Fig. 1. The sequence of the large subunits is identical across different plant species. Using UniProtKB Align, the polypeptide chains of the large RuBisCO subunit obtained from spinach, alfalfa and sunflower (Helianthus annuus) containing 473, 472 and 483 amino acid residues, respectively, showed $89.5 \%$ sequence homology and 434 identical positions. Conversely, the small subunits of plant RuBisCO contain about 123 amino acid residues with less sequence homology; using the example above, 41.6\% homology and 75 identical positions were observed for the small chain. RuBisCO has a net negative charge at neutral $\mathrm{pH}$ with isoelectric point $(\mathrm{pI})$ of 4.4-4.7, for spinach, maize, cotton and tobacco RuBisCO, and a large charge/mass ratio that promotes its tendency to bind cations (Barbeau \& Kinsella, 1988). The protein is hydrophobic with a relative hydrophobicity value of about 1,275 cal/residue (Barbeau \& Kinsella, 1988). From calculated values of the grand average of hydropathicity (GRAVY), alfalfa RuBisCO large subunit is more hydrophobic than the small subunit due to its higher total hydrophobic amino acid content (Table 1). Native alfalfa RuBisCO contains one free sulfhydryl group per protomer and others localized within the structure in the form of disulphide bridges (Barbeau \& Kinsella, 1988). The predominant amino acid residues in 
alfalfa RuBisCO include alanine (A), glycine (G) and leucine (L) for the large subunit, and glutamate (E) and leucine (L) for the small subunit (Table 1). The preponderance of hydrophobic amino acids makes RuBisCO attractive for some food applications, particularly as a starting material for producing hydrophobic bioactive peptides.

\section{Technologies for RuBisCO extraction}

Food-grade proteins are mainly derived from their natural sources or from animal-based or microbial systems, where animal cells or microbes are cultivated in fermenters (Twyman, Schillberg, \& Fischer, 2005). Protein extractions from animal and microbe-based systems is typically not laborious especially with the direct secretion of the proteins into growth media. Conversely, the extraction of plant proteins such as RuBisCO often requires maceration to breakdown the plant cell wall and the addition of protease inhibitors during extraction to reduce RuBisCO degradation. These processes constitute laborious steps, which are perceived as drawbacks in the extraction of plant proteins intended for use in food formulation. Furthermore, the extracted RuBisCO often contains chlorophyll, which leaves a lingering greenish colour on the final protein product. This limits the wider use of the protein extracts in the food industry (van de Velde, Alting, \& Pouvreau, 2011a) since the green colour can affect consumer acceptability of food products. Despite these perceived drawbacks, the interest in extracting plant-based proteins is on the rise due to some of its advantages over animal and microbial proteins. Safety is of a major concern when selecting the source of proteins used in food applications. Based on this, plant systems are considered safe, cheaper to maintain and upscaling of production is easier when compared to animal and microbial systems (Buyel, Twyman, \& Fischer, 2015; Sabalza, Christou, \& Capell, 2014). Nevertheless, the challenges of high-yield extraction and recovery of plant-based proteins from their food matrices still exist.

There has been promising development in food-grade extraction technologies for RuBisCO and other plant proteins. Extraction of plant proteins is often undertaken using standard methodologies (Fig. 2). These include precipitation with salt (e.g. ammonium sulphate) or 
solvent (e.g. acetone), followed by polishing steps involving combinations of chromatographic techniques such as ion-exchange, hydrophobic interaction, gel filtration, and affinity chromatography using immobilized antibody against RuBisCO (Kim et al., 2013; Warren, Adams, \& Chen, 2000; Weaver, 2010). As with other proteins, electrophoretic techniques such as sodium dodecyl sulfate-polyacrylamide gel and capillary electrophoresis have also been used in separating and visualizing the two subunits of RuBisCO. Often, purification steps are needed to remove impurities after RuBisCO extraction. For instance, Warren et al. (2000) reported that the polyphenol impurities observed in a RuBisCO extract was effectively removed using insoluble polyvinylpolypyrrolidone. When used, optimization of purification steps is important to avoid protein adsorption onto the separating material in order to maximize protein recovery and yield.

The methods and technologies used in plant protein extractions are usually optimizations of decades-old procedures. Interestingly, Chibnall (1939) published a simple but effective protocol for extracting proteins via pre-soaking of intact leaves in ethyl acetate followed by repeated cycles of soaking in water and then squeezing. The solvent treatment affords changes in the semi-permeability of the cell membranes and allows the selective removal of soluble low molecular weight non-protein nitrogenous compounds. The plant proteins are then extracted using standard extraction techniques following maceration of the leaves (Chibnall, 1939; Wildman, 2002). This technique improves the extraction efficiency of plant leaf proteins and makes the downstream purification less laborious. This method can be useful for supplying RuBisCO material but the use of organic solvents may limit its application in food. Moreover, Kim et al. (2013) recently reported the use of protamine sulphate for RuBisCO precipitation from soybean leaves. This method effectively extracts both subunits of RuBisCO in a fast, simple and economical process. Kobbi et al. (2017) also fractionated RuBisCO from industry-generated alfalfa green juice at about $90 \%$ purity using ammonium hydroxide and sodium hydroxide extraction followed by precipitation at $\mathrm{pH}$ 3. Tenorio et al. (2017) also combined solvent extraction and Triton X-114 phase partitioning for protein extraction from 
sugar beet leaves leading to enhanced protein purity and selective fractionation (Angelica Tamayo Tenorio, Boom, \& Goot, 2017). Moreover, differential solubility of RuBisCO subunits at low $\mathrm{pH}$ has facilitated the separation of the subunits and recovery of $48 \%$ of the small subunit at $98 \%$ purity (Trovaslet et al., 2007). These methods can easily be adapted for a wide applicability in extracting RuBisCO from leaves of other plants such as Arabidopsis, rice, alfalfa and maize.

Protein yield or recovery is a key factor in assessing the efficiency of an extraction method from different sources. Plants generally produce low levels of protein and this is one drawback in the adoption of molecular farming as an alternative to animal-based or microbial protein production (Sabalza et al., 2014). Obtaining high protein yields during scale up is a major goal of the industry and this is attainable during upstream production or downstream processing. The latter is a critical part of the process, and the most expensive for recombinant protein processes with estimated cost of $57 \%$ of the total production cost when using the bioreactor approach (Wilken \& Nikolov, 2012). Downstream processing is the recovery of highly purified proteins from plant matrices (Łojewska, Kowalczyk, Olejniczak, \& Sakowicz, 2016), some of which are considered plant wastes and "undesirable" for food applications. Recently, Dotsenko and Lange (2017) achieved 95\% protein recovery (with RuBisCO as the major protein) with consecutive protease and carbohydrase treatments from $400 \mathrm{mg}$ each of white clover and ryegrass screw press pulp biomass, compared to $40 \%$ and $80 \%$ protein recoveries with aqueous extraction $(\mathrm{pH}$ 8.0) and protease only treatment, respectively. Furthermore, thermal precipitation or heat coagulation has been used to separate soluble and insoluble leaf proteins from plant materials, with high yields of RuBisCO recovered in the soluble fraction (Tenorio, Gieteling, De Jong, Boom, \& Van Der Goot, 2016; van de Velde, Alting, \& Pouvreau, 2011b). In one instance, the process involves mechanical disruption of 40-80 wt.\% of plant leaf materials for cell lysis, pressing and centrifugation to recover the juice, heating at $50-80^{\circ} \mathrm{C}$ to coagulate green proteins, and chlorophyll and carotene removal using activated carbon (van de Velde et al., 2011b). These steps resulted in the recovery of a powder containing $>90 \%$ undenatured $\mathrm{RuBisCO}$ and $<0.1 \%$ 
chlorophyll from 50-1,000 kg plant leaf dry matter (batch process) or 50-2,000 kg dry matter/h (continuous process); the protein recovery and purity varied with different amounts of starting materials and processing conditions used (van de Velde et al., 2011b). Therefore, the methods still need to be optimized for industrial application to enhance the extraction and high yield recovery of RuBisCO especially from neglected and underutilized plant leaf materials.

\section{Biological activities of RuBisCO-derived peptides}

\subsection{Antihypertensive properties}

Food protein-derived peptides have been widely explored for their antihypertensive properties. Antihypertensive peptides play important role in regulating blood pressure mostly through the renin-angiotensin system (RAS) and the kinin-nitric oxide system pathways (Udenigwe \& Aluko, 2012). In RAS, angiotensinogen is converted to angiotensin (Ang) I by renin, and Ang I is then converted to Ang II by angiotensin I-converting enzyme (ACE). High vascular concentration of Ang II, which regulates blood pressure, can lead to excessive blood vessel contraction resulting in high blood pressure. Therefore, inhibition of the enzymatic activities of renin and ACE can regulate Ang II production and lead to blood pressure lowering effects during hypertension. Moreover, in kinin-nitric oxide system, bradykinin induces the release of intracellular calcium that activates endothelial nitric oxide synthase, which catalyzes the production of nitric oxide, a potent vasodilator (Bjornstad-Ostensen \& Berg, 1994). ACE degrades bradykinin and, as such, excessive enzyme activity will inhibit vasodilation and activate vasoconstriction. Antihypertensive peptides execute their physiological activity partly by inhibiting ACE activity.

Peptides derived from enzymatic hydrolysis of RuBisCO have shown antihypertensive properties by inhibiting the in vitro activity of ACE and lowering blood pressure in hypertensive animals. For instance, hydrolysates of alfalfa white protein concentrates (containing $65 \%$ RuBisCO) treated with Delvolase $\AA$ (DSM Food Specialties, Seclin, France), a protease preparation obtained from Bacillus licheniformis, inhibited ACE activity in vitro with half-maximal inhibitory concentration ( $\mathrm{IC}_{50}$ ) value of $8.8 \mu \mathrm{g} / \mathrm{mL}$ (Kapel, Chabeau, et al., 2006). 
Oral administration of $500 \mathrm{mg} / \mathrm{kg}$ body weight of the crude hydrolysate lowered the systolic blood pressure of spontaneously hypertensive rats (SHR) by $29.9 \mathrm{mmHg}$ at $4 \mathrm{~h}$ (Kapel, Chabeau, et al., 2006). Fractionation of the hydrolysate resulted in the identification of a dipeptide VW as a major active compound (Kapel, Chabeau, et al., 2006). VW had earlier been found to lower the systolic blood pressure of SHR by $10.8 \mathrm{mmHg}$ after $2 \mathrm{~h}$ of orally administering the peptide at 7.5 $\mathrm{mg} / \mathrm{kg}$ body weight (Marczak et al., 2003). This dipeptide is present in alfalfa RuBisCO large subunit at positions f67-68, f382-383 and f459-460, and in the small subunit at f60-61. Apart from the bacterial enzyme, pepsin and a combination of pepsin-pancreatin produced most of the known RuBisCO hydrolysates and released peptides that exhibited ACE inhibitory activities. Notably, some of the peptides discovered from spinach RuBisCO hydrolysates, including large subunit-derived peptides MRWRD (f210-214), MRW (rubimetide, f210-212) and LRIPVA (f136-141), and small subunit-derived peptide IAYKPAG (f116-122), inhibited ACE activity with $\mathrm{IC}_{50}$ values of $2.1,0.6,0.38$ and $4.2 \mu \mathrm{M}$, respectively (Yang, Marczak, Yokoo, Usui, \& Yoshikawa, 2003). Peptides MRW, MRWRD (both at $30 \mathrm{mg} / \mathrm{kg}$ body weight) and IAYKPAG (at $100 \mathrm{mg} / \mathrm{kg}$ body weight) were also found to lower systolic blood pressure of SHR by 20, 13.5 and $15 \mathrm{mmHg}$, respectively (LRIPVA was inactive in vivo), at 2 or $4 \mathrm{~h}$ post oral administration (Yang et al., 2003). These activities can be partly due to ACE inhibitory activities of the peptides in the vascular endothelium of the rats, assuming they were orally bioavailable in their native forms. On the other hand, using isolated rat mesenteric artery, it was demonstrated that the hypotensive and vasorelaxing activity of peptide MRW are also mediated by endothelin-derived factor other than nitric oxide, rather than only ACE inhibition. This effect was found to be mediated by prostaglandin $\mathrm{D}_{2}$ (PGD2) and its $\left(\mathrm{DP}_{1}\right)$ receptor (Zhao, Usui, Ohinata, \& Yoshikawa, 2008). This biological property would be important in managing hypertension associated with vascular dysfunction and metabolic diseases.

Regardless of the blood pressure lowering mechanism, the ACE-inhibiting RuBisCO peptides mostly need to be transported across both apical and basolateral sides of the intestinal cell barrier and be bioavailable in adequate amounts in the vascular system in order to exert their 
blood pressure-lowering activities. Moreover, certain gut microbes have impact on the blood pressure and vascular function of animal models of hypertension (Jose \& Raj, 2015; Karbach et al., 2016). Therefore, it is possible that the peptides will interact with the microbiota to regulate blood pressure without being absorbed into blood circulation. Since the peptides are generated with gastrointestinal proteases, it is likely that the antihypertensive and possibly other bioactive peptides are also produced during normal consumption and gut processing of RuBisCO from diets containing green vegetables.

\subsection{Opioid properties of $\mathrm{RuBisCO}$ peptides}

Opioid receptors are specialized G protein-coupled receptors found in the central and peripheral nervous, immune and endocrine systems. These receptors bind to specific ligands to regulate various biological processes, which can induce anti-nociceptive and anxiolytic activities, as well

as respiratory depression and gastrointestinal motility reduction (Teschemacher, 2003). Certain food protein-derived peptides are known to be opioid receptor ligands and, thus, can trigger some of the aforementioned biological effects (Korhonen \& Pihlanto, 2006; Teschemacher, 2003; Teschemacher, Koch, \& Brantl, 1997). Opioid peptides also participate in the absorption processes in the gut by modulating gastrointestinal functions such as smooth muscle contraction and intestinal transport of electrolytes (Korhonen \& Pihlanto, 2006; Teschemacher, 2003). Opioid activity of peptides may be agonistic or antagonistic and RuBisCO has been highlighted as a food protein source of opioid peptides (Teschemacher, 2003; Perlikowska \& Janecka, 2017). In fact, antihypertensive activity of alfalfa white protein (RuBisCO-rich) hydrolysate was proposed to be partly due to its opioid receptor-binding mechanism based on the loss of its relaxant effect in the presence of an opioid receptor antagonist in isolated rabbit ileum (Kapel, Chabeau, et al., 2006).

Moreover, rubiscolin-6 (YPLDLF) derived from spinach RuBisCO (f101-106, large subunit) independently exhibited anxiolytic effect mediated by $\sigma_{1}$ and dopamine $\mathrm{D}_{1}$ receptors (Yang et al., 2001; Hirata et al., 2007). To exert this activity, rubiscolin-6 first binds to $\delta$-opioid receptor 
resulting in the activation of $\sigma_{1}$ receptor-dependent mechanism, which releases dopamine and stimulates $\mathrm{D}_{1}$ receptors to mediate anxiolytic-like activity (Hirata et al., 2007). Both spinach RuBisCO-derived rubisconlin-5 (YPLDL, f101-105, large subunit) and rubiscolin-6 contain the sequence YPL. Opioid peptides typically have the YPX sequence where $\mathrm{X}$ is an aromatic amino acid, e.g. bovine $\beta$-casomorphin-8 (YPFPGPIP). Therefore, the substitution of $\mathrm{X}$ with an aliphatic amino acid, as found in the RuBisCO-derived peptides, did not lead to loss of opioid activity (Yang et al., 2001). In a later study, the following modifications of rubiscolin-6: Leu3 $\rightarrow$ Ile or Met, Phe $6 \rightarrow$ Val, and combined Leu3 $\rightarrow$ Met/ Phe6 $\rightarrow$ Val was found to increase opioid activity by 4, 10 and 20 times, respectively, when evaluated using the mouse vas deferens assay (Yang, Sonoda, Chen, \& Yoshikawa, 2003). The peptide resulting from the latter modification, YPMDLV, showed the lowest binding activity to $\delta$-opioid receptor $\left(\mathrm{IC}_{50} 0.12 \mu \mathrm{M}\right)$ and anti-nociceptive activity in ddY mice when compared to the original rubiscolin-6 (Yang, Sonoda, et al., 2003). This demonstrates the importance of amino acid residues at positions 3 and 6 in the peptide activity.

Rubiscolin-6 from spinach RuBisCO also effectively enhanced memory consolidation in mice, an activity that was also blocked by the $\delta$-opioid receptor antagonist (Yang, Kawamura, \& Yoshikawa, 2003). Recently, antihypertensive rubimetide from spinach RuBisCO was also found to exhibit its anxiolytic effect in ddY mice through the binding of formyl peptide receptor (FPR)2, which induces various biological processes, and the $\mathrm{PGD}_{2}-\mathrm{DP}_{1}$ receptor, adenosine and its $A_{2 A}$ receptor, as well as the $\gamma$-aminobutyric acid $(\mathrm{GABA})-\mathrm{GABA}_{\mathrm{A}}$ receptor process (Zhao, Sonada, Yoshikawa, Yoshikawa, \& Ohinata, 2016). Evidence of in vivo effects in these studies demonstrates that the peptides or their derivatives are bioavailable to exert opioid-like physiological effects in the animals, and underscores the need for further characterization of the peptide release in the gut during RuBisCO digestion, their physiological distribution and molecular interactions with the nervous system.

\subsection{Food intake-stimulating activity of RuBisCO peptides}


Peptide hormones such as gastrin and cholecystokinins are involved in stimulating the release of digestive enzymes in the gut. These secretagogue molecules are important in controlling food intake and appetite control. Using serum gastrin radioimmunoassay, a 1-1.85 kDa peptide fraction derived from pepsin hydrolyzed small alfalfa RuBisCO subunit demonstrated secretagogue activity at $14.2 \mathrm{pg}$ gastrin equivalent/mg dry mass, which was 8.5 times higher than the activity of the crude hydrolysate (Trovaslet et al., 2007). Moreover, rubiscolin-6 was found to stimulate increased food intake in mice in a process that was proposed to be mediated by lipocallin-type prostaglandin D synthase, $\mathrm{DP}_{1}$ and neuropeptide $\mathrm{Y}$ receptor $\mathrm{Y} 1$ (Kaneko et al., 2012). Interestingly, feeding the hexapeptide to 27-month old (aged) mice stimulated more food intake compared to observation with similar treatment in younger (15-month old) mice (Miyazaki et al., 2014). This indicates the need to further evaluate the potential of the RuBisCO peptide for improving food intake and reducing the incidence of "anorexia of aging" and associated undernutrition in the elderly.

\subsection{Antioxidative properties of RuBisCO peptides}

Free radicals and reactive oxygen species (ROS), produced during metabolic processes and oxidative stress, are deleterious to cells and tissues when present in excess amounts. Excessive generation of ROS results in oxidative damage of biological macromolecules such as lipids, proteins and DNA leading to several complications and health conditions (Betteridge, 2000). These damages can be curtailed by adequate supply of exogenous antioxidants in the diet, which can complement the cellular antioxidant machinery. Food-derived peptides have been extensively investigated for their antioxidative properties in vitro, in cell cultures and in animal models (Samaranayaka \& Li-Chan, 2011). Enzymatic hydrolysates of RuBisCO (90\% purity) showed strong in vitro antioxidative capacity by dose-dependently inhibiting linoleic acid oxidation, reducing ferric ion, and scavenging a radical cation (Kobbi et al., 2017). Moreover, Bondu et al. (2015) reported that a majority (about 60\%) of peptides identified in antioxidative hydrolysate fractions of red seaweed, Solieria chordalis, were derived from RuBisCO. As with 
most antioxidant peptides, there is a dearth of detailed structural and molecular explanations of the basis for these bioactivities. This is a particularly important consideration as RuBisCO subunits have low amounts of electron-donating (reducing) amino acids such as cysteine (Table 1). However, the protein subunits have about $5.3 \%$ phenylalanine residues that, if present in fractionated peptides, can trap ROS and free radicals to form stable hydroxytyrosine derivatives. In fact, our recent study identified a possibly antioxidative dipeptide (FC) from in silico analysis of plant and microalgae RuBisCO large subunits (f220-221) based on a predictive score and also the presence of both phenylalanine and cysteine residues in the structure (Je, Cho, Gong, \& Udenigwe, 2015). As expected, FC was found to suppress cellular ROS formation and lipid peroxidation with increased antioxidative catalase and superoxide dismutase 1 expression in oxidative-stressed cultured hepatocytes, as well as increased intracellular glutathione levels in normal cells (Je et al., 2015). Similar antioxidative activities would likely be obtained with the myriad of peptides generated from RuBisCO hydrolysis by endogenous and exogenous proteases considering the diverse structural functionalities and mechanisms of antioxidative peptides. Beside health promotion, the RuBisCO peptides can also find important applications in limiting oxidative damages that occur during food processing and storage leading to the extension of food product stability and shelf life.

\subsection{Antibacterial properties of RuBisCO peptides}

Some peptides derived from food proteins also exert antimicrobial activities against pathogenic microorganisms (Haque \& Chand, 2008) and thereby provide a possible natural alternative to synthetic antibiotics. There is emerging evidence on the antimicrobial properties of RuBisCO-derived peptides. For instance, high concentrations (up to $30 \mathrm{mg} / \mathrm{mL}$ ) of pepsin-hydrolyzed isolated small RuBisCO subunit and its fraction exhibited partial bacteriostatic (and not bactericidal) activity against pathogenic Gram negative bacteria, Salmonella arizonae and Shigella sonnei with maximum inhibition zone diameter of about 10 mm (Trovaslet et al., 2007). This indicates that the active antimicrobial peptides within the 
fractions may need to be purified to enhance the activity. To support this proposal, RuBisCO large subunit-derived peptides ELAAAC (f454-459), LRDDF (f349-353) and MDN (472-474), as well as their parent hydrolysate and fractions obtained by hydrolysis of RuBisCO with pepsin and purification, were found to exhibit antibacterial activity (Kobbi et al., 2015). The activity was observed against Gram negative (Escherichia coli) and Gram positive (Micrococcus luteus, Listeria innocus and Bacillus subtilis) bacteria with minimal inhibitory concentrations of 2.62-5.27 mM. The best effects were exhibited by tripeptide MDN against $L$. innocum and hexapeptide ELAAAC against M. luteus and L. innocum (Kobbi et al., 2015). These peptides possess structural features that differ from those of typical cell membrane-disrupting amphipathic/cationic antimicrobial peptides, and are therefore expected to display different functional mechanisms in the bacteria. The antimicrobial RuBisCO hydrolysates and peptides can be relevant in food preservation by limiting microbial growth and associated spoilage, and in eliminating food-borne pathogens from the food system.

\section{Prospective release of other bioactive peptides from RuBisCO}

Bioinformatics, using web-based tools, is emerging as a useful approach for studying the occurrence and biological roles of food peptides (Udenigwe, 2014, Maestri et al., 2016). Using this approach, many RuBisCO peptide sequences, previously isolated from other sources, have been found to show various bioactivities other than the aforementioned properties (Udenigwe, Gong, \& Wu, 2013). As shown in Table 3, alfalfa RuBisCO large and small subunits contain bioactive peptides that exhibit 12 and 13 different health-related bioactivities, respectively. The occurrence frequencies $(A)$ of the peptides in RuBisCO are generally similar or lower than those of bovine $\beta$-casein, a typical bioactive peptide source, but the RuBisCO proteins are better sources of neuropeptides and peptides with ubiquitin-mediated proteolysis activating, bacterial permease ligand, and hypotensive activities (Table 3). Notably, the plant RuBisCO subunits have high $A$ values for dipeptidyl peptidase (DPP)-IV inhibitors. The $A$ values for this bioactivity are an order of magnitude higher than those reported for large RuBisCO subunit from various 
seaweed (Caulerpa) species (Agirbasli \& Cavas, 2017). This observation in our study is due to the high content of hydrophobic amino acid residues especially alanine and proline in the plant RuBisCO, which play major structural roles for DPP-IV inhibition (Nongonierma \& FitzGerald, 2016). DPP-IV inhibitors are important in preventing the inactivation of incretins and promoting insulin secretion and glucose metabolism. However, DPP-IV inhibition is yet to be reported for RuBisCO peptides.

Despite the promising outlook, the bioactivities in Table 3 can only be observed on successful release of the peptides from the RuBisCO subunits. Using DPP-IV as an example, Table 4 shows the frequency of release of peptides with DPP-IV inhibitory activity by selected proteases $\left(A_{E}\right)$ and the relative frequency of release of fragments with the bioactivity by each protease $(W)$, as proposed by Minkiewicz et al. (2008). When classified based on functional mechanisms, cysteine proteases (ficin and papain) and metalloprotease (thermolysin) released more DPP-IV inhibiting peptides from the alfalfa large RuBisCO subunit when compared to serine (chymotrypsin A, trypsin) and aspartate proteases (pepsin). The results are similar or better than the release of these peptides, by same proteases, from bovine $\beta$-casein. This is likely due to the preference of ficin, papain and thermolysin in cleaving peptide bond of proteins near hydrophobic amino acid residues, which are needed for potent DPP-IV inhibition. Conversely, ficin and chymotrypsin A are better in releasing DPP-IV inhibitors from the small RuBisCO subunit (Table 4). These possibilities, if confirmed experimentally, will expand the relevance of RuBisCO-derived peptides as functional ingredients for multiple health and food applications.

\section{Fractionation and recovery of RuBisCO peptides}

During hydrolysis of RuBisCO, it is important to optimize parameters such as reaction temperature, duration, $\mathrm{pH}$, ionic strength, enzyme-substrate ratio, and use of single or multiple enzymes. This will ensure the production of high yields of particular peptides with the desired bioactivity. For instance, pepsin released $0.17 \%$ mol rubiscolin-5 per mol RuBisCO large subunit, but further hydrolysis with leucine aminopeptidase increased the peptide yield by 29 folds to $5 \%$ 
mol (Yang et al., 2001). After hydrolysis, bioactive peptides can be left in the complex hydrolysate matrix for use in food product formulation. However, matrix interactions may lead to low abundance of peptides of interest, which can minimize their bioactivity within the hydrolysate (Udenigwe \& Fogliano, 2017). In such cases, bioactive peptides often need to be recovered by fractionation and purification prior to structural characterization and bioactivity evaluation. Bioactive peptides have been fractionated from hydrolysates by solid-phase extraction and chromatographic techniques (size exclusion, ion exchange, reversed-phase) based on molecular size, charge and hydrophobicity (Chen, Mant, \& Hodges, 2007; Hayes, Ross, Fitzgerald, Hill, \& Stanton, 2006; Udenigwe \& Aluko, 2012). Membrane chromatography involving the use of ligand-bound membranes has also been used for the purification of small proteins and peptides based on ion-exchange and hydrophobic interaction principles (Saxena, Tripathi, Kumar, \& Shahi, 2009).

Bioactive peptides derived from RuBisCO have been purified from their parent hydrolysates mostly by size exclusion and reverse-phase high performance liquid chromatography (Kapel, Chabeau, et al., 2006; Kapel, Rahhou, Lecouturier, Guillochon, \& Dhulster, 2006; Kobbi et al., 2015, 2017; Trovaslet et al., 2007; Yang et al., 2003). Although these purification steps lead to relatively pure peptides, scale up of the processes for industrial application is currently not feasible due to high cost and complex analytical set-ups involved. Simpler methods have also been explored as cheaper alternatives. For instance, an antimicrobial peptide fraction was separated from RuBisCO hydrolysate by precipitation under ionic strength and $\mathrm{pH}$ effect, which involves adding $\mathrm{NaCl}$ and adjusting the hydrolysate solution to neutral $\mathrm{pH}$ to precipitate the peptides (Kobbi et al., 2015). However, liquid chromatography was later used to obtain more purified peptides from the fraction. Electrodialysis coupled with membrane ultrafiltration (EDUF) is another technique used to recover the antihypertensive dipeptide VW from alfalfa white protein $(\mathrm{RuBisCO})$ hydrolysate with high transmission rates using a semi-pilot process that can be translated in the industry (Firdaous et al., 2009, 2010). Furthermore, VW was also fractionated from a similar hydrolysate with $97 \%$ recovery $(30.7 \mathrm{mg}, 10.9 \%$ purity from $1 \mathrm{~g}$ of 
hydrolysate) using a mixed ion-exchange centrifugal partition chromatography on a quaternary biphasic solvent system and a lipophilic cationic exchange column (Boudesocque et al., 2012). These processes are promising but the peptide extraction still needs to be scaled up industrially to obtain larger quantities with high purity. Recently, perfusion chromatography with the use of monolithic columns was proposed as a cost-effective and scalable strategy for the purification of bioactive peptides (Agyei, Ongkudon, Wei, Chan, \& Danquah, 2016). This technique can be explored for obtaining large amounts of purified RuBisCO peptides.

\section{Conclusion and future direction}

RuBisCO remains the most abundant protein on earth and has been explored as a sustainable source of bioactive peptides. This is supported by in vitro and in vivo evidence of bioactivities of RuBisCO-derived peptides, and by information derived from in silico predictions. Extraction efficiency and recovery of high yields are major determinants of industrial utilization of protein isolates in developing food products. Therefore, efforts should be directed towards obtaining more efficient, green extraction and recovery technologies to scale up industrial production of RuBisCO isolates, especially from non-traditional sources such as plants that are not commonly consumed as food, neglected and underutilized crops, and vegetable food wastes. This support the maximum use of renewable natural resources, sustainability and bioeconomy development at the local and global levels. Although RuBisCO-derived peptides have been evaluated for health promotion and disease prevention, the protein also has potential for use as a functional ingredient in various other food applications. It is also likely that RuBisCO peptides generated during gastrointestinal food digestion contribute to some known health benefits associated with vegetable consumption. Furthermore, human studies need to be conducted to substantiate the aforementioned preclinical bioactivities of RuBisCO peptides. On a long-term basis, the use of leaves from non-traditional food sources as a reliable source of RuBisCO needs substantial research investment in order to limit competition with food crops. The expected end goal is the sustainable production of RuBisCO, its conversion into bioactive peptides, and translation of the 
peptides into marketable functional foods for use in prevention and management of health conditions.

\section{Acknowledgement}

The authors thank the Natural Sciences and Engineering Research Council of Canada (NSERC) for providing Individual Discovery Grants to support the fundamental food protein and peptide research programs of CCU (grant number RGPIN 435865-2013) and REA (grant number RGPIN 249890-13).

\section{References}

Agirbasli, Z., \& Cavas, L. (2017). In silico evaluation of bioactive peptides from the green algae Caulerpa. Journal of Applied Phycology, 29, 1635-1646.

Agyei, D., Ongkudon, C. M., Wei, C. Y., Chan, A. S., \& Danquah, M. K. (2016). Bioprocess challenges to the isolation and purification of bioactive peptides. Food and Bioproducts Processing, 98, 244-256.

Ale, M. T., Mikkelsen, J. D., \& Meyer, A. S. (2011). Important determinants for fucoidan bioactivity: A critical review of structure-function relations and extraction methods for fucose-containing sulfated polysaccharides from brown seaweeds. Marine Drugs, 9, 21062130.

Andersson, I., \& Backlund, A. (2008). Structure and function of Rubisco. Plant Physiology and Biochemistry, 46, 275-291.

Barbeau, W. E., \& Kinsella, J. E. (1988). Ribulose bisphosphate carboxylase/oxygenase (rubisco) from green leaves - potential as a food protein. Food Reviews International, 4, 93-127.

Betteridge, D. J. (2000). What is oxidative stress? Clinical and Experimental, 49, 3-8.

Bjornstad-Ostensen, A., \& Berg, T. (1994). The role of nitric oxide, adrenergic activation and kinin-degradation in blood pressure homeostasis following an acute kinin-induced hypotension. British Journal of Pharmacology, 113, 1567-1573.

Bondu, S., Bonnet, C., Gaubert, J., Deslandes, É., Turgeon, S. L., \& Beaulieu, L. (2015). Bioassay-guided fractionation approach for determination of protein precursors of proteolytic bioactive metabolites from macroalgae. Journal of Applied Phycology, 27, 2059-2074.

Boudesocque, L., Kapel, R., Paris, C., Dhulster, P., Marc, I., \& Renault, J. H. (2012). Concentration and selective fractionation of an antihypertensive peptide from an alfalfa 
white proteins hydrolysate by mixed ion-exchange centrifugal partition chromatography. Journal of Chromatography B: Analytical Technologies in the Biomedical and Life Sciences, 905, 23-30.

Buyel, J. F., Twyman, R. M., \& Fischer, R. (2015). Extraction and downstream processing of plant-derived recombinant proteins. Biotechnology Advances, 33, 902-913.

Chakrabarti, S., Jahandideh, F., \& Wu, J. (2014). Food-derived bioactive peptides on inflammation and oxidative stress. BioMed Research International, DOI: $10.1155 / 2014 / 608979$

Chen, Y., Mant, C. T., \& Hodges, R. S. (2007). Preparative reversed-phase high-performance liquid chromatography collection efficiency for an antimicrobial peptide on columns of varying diameters (1 mm to $9.4 \mathrm{~mm}$ I.D.). Journal of Chromatography A, 1140, 112-120.

Chibnall, A. C. (1939). Protein Metabolism in the Plant. New Haven, Connecticut: Yale University Press.

Dotsenko, G., \& Lange, L. (2017). Enzyme enhanced protein recovery from green biomass pulp. Waste and Biomass Valorization, 8, 1257-1264.

Ejike, C. E. C. C., Collins, S. A., Balasuriya, N., Swanson, A. K., Mason, B., \& Udenigwe, C. C. (2017). Prospects of microalgae proteins in producing peptide-based functional foods for promoting cardiovascular health. Trends in Food Science and Technology, 59, 30-36.

Maestri, E., Marmiroli, M., \& Marmiroli, N. (2016). Bioactive peptides in plant-derived foodstuffs. Journal of Proteomics, 147, 140-155.

Firdaous, L., Dhulster, P., Amiot, J., Doyen, A., Lutin, F., Vézina, L. P., \& Bazinet, L. (2010). Investigation of the large-scale bioseparation of an antihypertensive peptide from alfalfa white protein hydrolysate by an electromembrane process. Journal of Membrane Science, $355,175-181$.

Firdaous, L., Dhulster, P., Amiot, J., Gaudreau, A., Lecouturier, D., Kapel, R., Lutin, F., Vézina, L.P., \& Bazinet, L. (2009). Concentration and selective separation of bioactive peptides from an alfalfa white protein hydrolysate by electrodialysis with ultrafiltration membranes. Journal of Membrane Science, 329, 60-67.

Haque, E., \& Chand, R. (2008). Antihypertensive and antimicrobial bioactive peptides from milk proteins. European Food Research and Technology, 227, 7-15.

Hayes, M., Ross, R. P., Fitzgerald, G. F., Hill, C., \& Stanton, C. (2006). Casein-derived antimicrobial peptides generated by Lactobacillus acidophilus DPC6026. Applied and Environmental Microbiology, 72, 2260-2264.

Hirata, H., Sonoda, S., Agui, S., Yoshida, M., Ohinata, K., \& Yoshikawa, M. (2007). Rubiscolin-6, a $\delta$ opioid peptide derived from spinach Rubisco, has anxiolytic effect via activating $\sigma 1$ and dopamine D1 receptors. Peptides, 28, 1998-2003. 
Howard, A., \& Udenigwe, C. C. (2013). Mechanisms and prospects of food protein hydrolysates and peptide-induced hypolipidaemia. Food \& Function, 4, 40-51.

Je, J. Y., Cho, Y. S., Gong, M., \& Udenigwe, C. C. (2015). Dipeptide Phe-Cys derived from in silico thermolysin-hydrolysed RuBisCO large subunit suppresses oxidative stress in cultured human hepatocytes. Food Chemistry, 171, 287-291.

Jose, P. A., \& Raj, D. (2015). Gut microbiota in hypertension. Current Opinion in Nephrology and Hypertension, 25, 403-409.

Kaneko, K., Lazarus, M., Miyamoto, C., Oishi, Y., Nagata, N., Yang, S., Yoshikawa, M., Aritake, K., Furuyashiki, T., Narumiya, S., Urade, Y., Ohinata, K., \& Urade, Y. (2012). Orally administered rubiscolin-6, a $\delta$ opioid peptide derived from Rubisco, stimulates food intake via leptomeningeal lipocallin-type prostaglandin D synthase in mice. Molecular Nutrition \& Food Research, 56, 1315-1323.

Kapel, R., Chabeau, A., Lesage, J., Riviere, G., Ravallec-Ple, R., Lecouturier, D., Wartelled, M., Guillochona, D., \& Dhulster, P. (2006). Production, in continuous enzymatic membrane reactor, of an anti-hypertensive hydrolysate from an industrial alfalfa white protein concentrate exhibiting ACE inhibitory and opioid activities. Food Chemistry, 98, 120-126.

Kapel, R., Rahhou, E., Lecouturier, D., Guillochon, D., \& Dhulster, P. (2006). Characterization of an antihypertensive peptide from an Alfalfa white protein hydrolysate produced by a continuous enzymatic membrane reactor. Process Biochemistry, 41, 1961-1966.

Karbach, S. H., Schönfelder, T., Brandão, I., Wilms, E., Hörmann, N., Jäckel, S., et al. (2016). Gut microbiota promote angiotensin II-induced arterial hypertension and vascular dysfunction. Journal of the American Heart Association, 5, e003698.

Kim, Y. J., Lee, H. M., Wang, Y., Wu, J., Kim, S. G., Kang, K. Y., Park, K. H., Kim, Y. C., Choi, I. S., Agrawal, G. K., Rakwal, R., \& Kim, S. T. (2013). Depletion of abundant plant RuBisCO protein using the protamine sulfate precipitation method. Proteomics, 13, 21762179.

Kobbi, S., Balti, R., Bougatef, A., Le Flem, G., Firdaous, L., Bigan, M., Chataigné, G., Chaabouni, S., Dhulster, P., \& Nedjar, N. (2015). Antibacterial activity of novel peptides isolated from protein hydrolysates of $\mathrm{RuBisCO}$ purified from green juice alfalfa. Journal of Functional Foods, 18, 703-713.

Kobbi, S., Bougatef, A., Le flem, G., Balti, R., Mickael, C., Fertin, B., Chaabouni, S., Dhulster, P., \& Nedjar, N. (2017). Purification and recovery of RuBisCO protein from alfalfa green juice: Antioxidative properties of generated protein hydrolysate. Waste and Biomass Valorization, 8, 493-504.

Korhonen, H., Pihlanto-Leppäla, A., Rantamäki, P., \& Tuomo, T. (1998). Impact of Pocessing on Bioactive Proteins and Peptides. Trends in Food Science and Technology, 9, 307-319. 
Korhonen, H., \& Pihlanto, A. (2003). Food derived bioactive peptide-opportunities for designing future foods. Current Pharmaceutical Designs, 9, 1297-1308.

Korhonen, H., \& Pihlanto, A. (2006). Bioactive peptides : Production and functionality. International Dairy Journal, 16, 945-960.

Li-Chan, E. C. (2015). Bioactive peptides and protein hydrolysates: research trends and challenges for application as nutraceuticals and functional food ingredients. Current Opinion in Food Science, 1, 28-37.

Łojewska, E., Kowalczyk, T., Olejniczak, S., \& Sakowicz, T. (2016). Extraction and purification methods in downstream processing of plant-based recombinant proteins. Protein Expression and Purification, 120, 110-117.

Maeda, N., Kitano, K., Fukui, T., Ezaki, S., Atomi, H., Miki, K., \& Imanaka, T. (1999). Ribulose bisphosphate carboxylase/oxygenase from the hyperthermophilic archaeon Pyrococcus kodakaraensis KOD1 is composed solely of large subunits and forms a pentagonal structure. Journal of Molecular Biology, 293, 57-66.

Marczak, E. D., Usui, H., Fujita, H., Yang, Y., Yokoo, M., Lipkowski, A. W., \& Yoshikawa, M. (2003). New antihypertensive peptides isolated from rapeseed. Peptides, 24, 791-798.

Martínez-Maqueda, D., Miralles, B., Recio, I., \& Hernández-Ledesma, B. (2012). Antihypertensive peptides from food proteins: a review. Food \& Function, 3, 350-361.

McClements, D. J., Decker, E. A., Park, Y., \& Weiss, J. (2009). Structural design principles for delivery of bioactive components in nutraceuticals and functional foods. Critical Reviews in Food Science and Nutrition, 49, 577-606.

Minkiewicz, P., Dziuba, J., Iwaniak, A., Dziuba, M., \& Darewicz, M. (2008). BIOPEP database and other programs for processing bioactive peptide sequences. Journal of AOAC International, 91, 965-980.

Miyazaki, Y., Kaneko, K., Iguchi, S., Mizushige, T., Kanamoto, R., Yoshikawa, M., Shixizu, T., $\&$ Ohinata, K. (2014). Orally administered $\delta$ opioid agonist peptide rubiscolin- 6 stimulates food intake in aged mice with ghrelin resistance. Molecular Nutrition and Food Research, 58, 2046-2052.

Morse, D., Salois, P., Markovic, P., \& Hastings, J. W. (1995). A nuclear-encoded form II RuBisCO in dinoflagellates. Science, 268, 1622-1624.

Nongonierma, A. B., \& FitzGerald, R. J. (2016). Prospects for the management of type 2 diabetes using food protein-derived peptides with dipeptidyl peptidase IV (DPP-IV) inhibitory activity. Current Opinion in Food Science, 8, 19-24.

Perlikowska, R., \& Janecka, A. (2017). Rubiscolins-highly potent peptides derived from plant proteins. Mini Reviews in Medicinal Chemistry, DOI:

$10.2174 / 1389557517666170426160703$ 
Rajendran, S. R. C. K., Ejike, C. E. C. C., Gong, M., Hannah, W., \& Udenigwe, C. C. (2017). Preclinical evidence on the anticancer properties of food peptides. Protein and Peptide Letters, 24, 126-136.

Sabalza, M., Christou, P., \& Capell, T. (2014). Recombinant plant-derived pharmaceutical proteins: current technical and economic bottlenecks. Biotechnology Letters, 36, 23672379.

Samaranayaka, A. G., \& Li-Chan, E. C. (2011). Food-derived peptidic antioxidants: A review of their production, assessment, and potential applications. Journal of Functional Foods, 3 , $229-254$.

Saxena, A., Tripathi, B. P., Kumar, M., \& Shahi, V. K. (2009). Membrane-based techniques for the separation and purification of proteins: An overview. Advances in Colloid and Interface Science, 145, 1-22.

Spreitzer, R. J., \& Salvucci, M. E. (2002). RUBISCO: Structure, regulatory interactions, and possibilities for a better enzyme. Annual Review of Plant Biology, 53, 449-475.

Sun, L. (2013). Peptide-Based Drug Development. Modern Chemistry \& Applications, 1, e103, doi: 10.4172/2329-6798.1000E103.

Rizzello, C. G., Tagliazucchi, D., Babini, E., Rutella, G. S., Saa, D. L. T., \& Gianotti, A. (2016). Bioactive peptides from vegetable food matrices: Research trends and novel biotechnologies for synthesis and recovery. Journal of Functional Foods, 27, 549-569.

Tabita, F. R. (1999). Microbial ribulose-1,5-bisphosphate carboxylase/oxygenase: a different perspective. Photosynthesis Research, 60, 1-28.

Taylor, T. C., \& Andersson, I. (1997). Structure of a product complex of spinach ribulose-1,5-bisphosphate carboxylase/oxygenase. Biochemistry, 36, 4041-4046.

Tenorio, A. T., Boom, R. M., \& Van Der Goot, A. J. (2017). Understanding leaf membrane protein extraction to develop a food- grade process. Food Chemistry, 217, 234-243.

Tenorio, A. T., Gieteling, J., De Jong, G. A., Boom, R. M., \& Van Der Goot, A. J. (2016). Recovery of protein from green leaves: Overview of crucial steps for utilisation. Food Chemistry, 203, 402-408.

Teschemacher, H. (2003). Opioid receptor ligands derived from food proteins. Current Pharmaceutical Design, 9, 1331-1344.

Teschemacher, H., Koch, G., \& Brantl, V. (1997). Milk protein-derived opioid receptor ligands. Biopolymers, 43, 99-117.

Trovaslet, M., Kapel, R., Ravallec-Ple, R., Mouni, F., Clarisse, M., Faille, C., Dhulster, P.,

Guillochon, D., \& Vercaigne-Marko, D. (2007). Secretagogue and bacteriostatic active fractions derived from a peptic hydrolysate of alfalfa $\mathrm{RuBisCO}$ small purified subunit. Journal of the Science of Food and Agriculture, 87, 534-540. 
Twyman, R. M., Schillberg, S., \& Fischer, R. (2005). Transgenic plants in the biopharmaceutical market. Expert Opinion on Emerging Drugs, 10, 185-218.

Udenigwe, C. C. (2014). Bioinformatics approaches, prospects and challenges of food bioactive peptide research. Trends in Food Science \& Technology, 36, 137-143.

Udenigwe, C. C., \& Aluko, R. E. (2012). Food Protein-Derived Bioactive Peptides : Production , Processing, and Potential Health Benefits. Journal of Food Science, 71, 11-24.

Udenigwe, C. C., Gong, M., \& Wu, S. (2013). In silico analysis of the large and small subunits of cereal RuBisCO as precursors of cryptic bioactive peptides. Process Biochemistry, 48 , 1794-1799.

Udenigwe, C. C., \& Fogliano, V. (2017). Food matrix interaction and bioavailability of bioactive peptides: Two faces of the same coin?. Journal of Functional Foods, 35, 9-12.

van de Velde, F., Alting, A., Pouvreau, L. (2011a). From waste product to food ingredient: The extraction of the abundant plant protein Rubisco, New Food, 14, 10-13.

van de Velde, F., Alting, A. C., \& Pouvreau, L. (2011b). Process for isolating a dechlorophyllized rubisco preparation from a plant material. WIPO Patent WO 2011/078671 A1.

Warren, C. R., Adams, M. A., \& Chen, Z. (2000). Is photosynthesis related to concentrations of nitrogen and Rubisco in leaves of Australian native plants? Functional Plant Biology, 27, $407-416$.

Weaver, D. (2010). Isolation and identification of Rubisco extracted from spinach leaves. Journal of IEST, 53, 18-23.

Whitney, S. M., \& Andrews, T. J. (1998). The $\mathrm{CO}_{2} / \mathrm{O}_{2}$ specificity of single-subunit ribulose-bisphosphate carboxylase from the dinoflagellate, Amphidinium carterae. Australian Journal of Plant Physiology, 25, 131-138.

Wildman, S. G. (2002). Along the trail from Fraction I protein to Rubisco (ribulose bisphosphate carboxylase-oxygenase). Photosynthesis Research, 73, 243-250.

Wilken, L. R., \& Nikolov, Z. L. (2012). Recovery and purification of plant-made recombinant proteins. Biotechnology Advances, 30, 419-433.

Yang, S., Kawamura, Y., \& Yoshikawa, M. (2003). Effect of rubiscolin, a $\delta$ opioid peptide derived from Rubisco, on memory consolidation. Peptides, 24, 325-328.

Yang, S., Sonoda, S., Chen, L., \& Yoshikawa, M. (2003). Structure-activity relationship of rubiscolins as $\delta$ opioid peptides. Peptides, 24, 503-508.

Yang, S., Yunden, J., Sonoda, S., Doyama, N., Lipkowski, A. W., Kawamura, Y., \& Yoshikawa, M. (2001). Rubiscolin, a $\delta$ selective opioid peptide derived from plant Rubisco. FEBS Letters, 509, 213-217.

Yang, Y., Marczak, E. D., Yokoo, M., Usui, H., \& Yoshikawa, M. (2003). Isolation and antihypertensive effect of angiotensin I-converting enzyme (ACE) inhibitory peptides from 
spinach Rubisco. Journal of Agricultural and Food Chemistry, 51, 4897-4902.

Yang, Y., Marczak, E. D., Yokoo, M., Usui, H., \& Yoshikawa, M. (2004). Antihypertensive properties of spinach leaf protein digests. Journal of Agricultural and Food Chemistry, 52, 2223-2225.

Zhao, H., Ohinata, K., \& Yoshikawa, M. (2008). Rubimetide (Met-Arg-Trp) derived from Rubisco exhibits anxiolytic-like activity via the DP1 receptor in male ddY mice. Peptides, $29,629-632$.

Zhao, H., Sonada, S., Yoshikawa, A., Yoshikawa, M., \& Ohinata, K. (2016). Rubimetide, humanin, and MMK1 exert anxiolytic-like activities via the formyl peptide receptor 2 in mice followed by the successive activation of DP1, A2A, and GABAA receptors. Peptides, $83,16-20$.

Zhao, H., Usui, H., Ohinata, K., \& Yoshikawa, M. (2008). Met-Arg-Trp derived from Rubisco lowers blood pressure via prostaglandin D2-dependent vasorelaxation in spontaneously hypertensive rats. Peptides, 29, 345-349.

\section{FIGURES}

Fig. 1. Structure of activated unliganded spinach RuBisCO; Large chain, green ribbons;

Small chain, blue ribbons. PDB file: 1AUS; DOI: 10.2210/pdb1aus/pdb; Primary reference (Taylor \& Andersson, 1997).

Fig. 2. Simplified schematic for the extraction of plant $\mathrm{RuBisCO}$ and production of RuBisCO hydrolysates and peptides 
TABLE 1. AMINO ACID COMPOSITION AND PROPERTIES OF ALFALFA RUBISCO LARGE AND SMALL SUBUNITS CALCULATED WITH UNIPROTKB PROTPARAM.

\begin{tabular}{lccccc}
\hline & \multicolumn{2}{c}{ Large subunit } & & \multicolumn{2}{c}{ Small subunit } \\
\cline { 2 - 3 } \cline { 5 - 6 } & No. of & \% & & No. of AA & $\%$ \\
& AA & & & & \\
\hline Ala & 48 & 10.2 & & 5 & 4.1 \\
Arg & 30 & 6.4 & & 7 & 5.7 \\
Asn & 15 & 3.2 & & 3 & 2.4 \\
Asp & 27 & 5.7 & & 5 & 4.1 \\
Cys & 8 & 1.7 & & 3 & 2.4 \\
Gln & 12 & 2.5 & & 5 & 4.1 \\
Glu & 33 & 7.0 & & 11 & 8.9 \\
Gly & 45 & 9.5 & & 7 & 5.7 \\
His & 14 & 3.0 & & 2 & 1.6 \\
Ile & 21 & 4.4 & & 7 & 5.7 \\
Leu & 39 & 8.3 & & 11 & 8.9 \\
Lys & 23 & 4.9 & & 9 & 7.3 \\
Met & 10 & 2.1 & & 2 & 1.6 \\
Phe & 23 & 4.9 & & 7 & 5.7 \\
Pro & 21 & 4.4 & & 9 & 7.3
\end{tabular}




\begin{tabular}{lccccc} 
Ser & 14 & 3.0 & 6 & 4.9 \\
Thr & 31 & 6.6 & 5 & 4.1 \\
Trp & 8 & 1.7 & 4 & 3.3 \\
Tyr & 17 & 3.6 & 8 & 6.5 \\
Val & 33 & & 7.0 & 7 & 5.7 \\
No. of AA & \multicolumn{2}{c}{472} & & \multicolumn{2}{c}{123} \\
pI & \multicolumn{2}{c}{6.10} & \multicolumn{2}{c}{6.73} \\
MW (Da) & 52,407 & \multicolumn{2}{c}{14,557} \\
GRAVY & -0.247 & \multicolumn{2}{c}{-0.438} \\
\hline
\end{tabular}

AA, amino acid; pI, theoretical isoelectric point; MW, molecular weight; GRAVY, grand average of hydropathicity 
TABLE 2. BIOACTIVE PEPTIDES DERIVED FROM PLANT RUBISCO.

\begin{tabular}{|c|c|c|c|c|c|c|c|}
\hline Sequence & Subunit & Source & Location & Protease & Fractionation & Bioactivity summary & Reference \\
\hline \multirow[t]{2}{*}{ MRWRD } & \multirow[t]{2}{*}{ Large } & \multirow[t]{6}{*}{ Spinach } & $210-214$ & \multirow{6}{*}{$\begin{array}{l}\text { Pepsin }+ \\
\text { pancreatin }\end{array}$} & \multirow{6}{*}{$\begin{array}{l}\text { RP-HPLC + } \\
\text { purification on } \\
\text { phenethyl silica, } \\
\text { cyanopropyl silica \& } \\
\text { nitrophenetyl columns }\end{array}$} & \multirow{6}{*}{$\begin{array}{l}\text { ACE inhibition \& SBP } \\
\text { lowering in hypertensive } \\
\text { rats (except LRIPVA); } \\
\text { Opioid activity (MRW) }\end{array}$} & Yang et al., 2003 \\
\hline & & & & & & & \multirow[t]{5}{*}{ Zhao et al., 2016} \\
\hline MRW & Large & & $210-212$ & & & & \\
\hline (rubimetide) & & & & & & & \\
\hline LRIPVA & Large & & $136-141$ & & & & \\
\hline IAYKPAG & Small & & $116-122$ & & & & \\
\hline \multirow{5}{*}{$\begin{array}{l}\text { YPLDL } \\
\text { (rubiscolin-5) } \\
\text { YPLDLF } \\
\text { (rubiscolin-6) }\end{array}$} & \multirow[t]{2}{*}{ Large } & \multirow[t]{5}{*}{ Spinach } & $101-105$ & \multirow{5}{*}{$\begin{array}{l}\text { Pepsin + leucine } \\
\text { aminopeptidase }\end{array}$} & RP-HPLC + & \multirow{5}{*}{$\begin{array}{l}\text { Opioid \& anxiolytic } \\
\text { activities; Food intake } \\
\text { stimulation (rubiscolin-6) }\end{array}$} & Hirata et al., 2007 \\
\hline & & & & & purification on & & Yang et al., 2001, \\
\hline & \multirow[t]{3}{*}{ Large } & & $101-106$ & & phenethyl silica & & $2003 b, c$ \\
\hline & & & & & column; Also & & Miyazaki et al., 2014 \\
\hline & & & & & synthesized & & \\
\hline \multirow[t]{4}{*}{ VW } & \multirow[t]{2}{*}{ Large } & \multirow[t]{4}{*}{ Alfalfa } & $67-68$ & \multirow[t]{4}{*}{ Delvolase } & Size-exclusion + & ACE inhibition \& SBP & Kapel et al., 2006a,b \\
\hline & & & $382-383$ & & RP-HPLC; & lowering in hypertensive & Marczak et al., 2003 \\
\hline & \multirow[t]{2}{*}{ Small } & & $459-460$ & & Electrodialysis with & rats & \multirow{2}{*}{$\begin{array}{l}\text { Firdaous et al., 2009, } \\
2010\end{array}$} \\
\hline & & & $61-61$ & & ultrafiltration & & \\
\hline ELAAAC & Large & Alfalfa & $454-459$ & Pepsin & RP-HPLC + & Antibacterial activity & Kobbi et al., 2015 \\
\hline LRDDF & Large & & $349-353$ & Pepsin & precipitation under & against Escherichia coli, & \\
\hline \multirow[t]{2}{*}{ MDN } & \multirow[t]{2}{*}{ Large } & & $472-474$ & \multirow[t]{2}{*}{ Pepsin } & \multirow[t]{2}{*}{ ionic \& pH effects } & Micrococcus luteus, Listeria & \\
\hline & & & & & & innocus \& Bacillus subtilis & \\
\hline \multirow[t]{3}{*}{$\mathrm{FC}$} & \multirow[t]{3}{*}{ Large } & \multirow{3}{*}{$\begin{array}{l}\text { Various plant } \\
\text { sources }\end{array}$} & \multirow[t]{3}{*}{$220-221$} & Thermolysin & \multirow[t]{3}{*}{ Synthesized } & Antioxidant activity in & \multirow[t]{3}{*}{ Je et al., 2015} \\
\hline & & & & (prediction & & hepatic cell culture treated & \\
\hline & & & & only) & & with an oxidant & \\
\hline
\end{tabular}

RP-HPLC, reverse phase-high performance liquid chromatography; ACE, angiotensin I-converting enzyme; SBP, systolic blood pressure 
4 TABLE 3. FREQUENCY OF OCCURRENCE OF BIOACTIVE

5 PEPTIDES IN THE LARGE AND SMALL SUBUNITS OF

6 ALFALFA RUBISCO COMPARED TO BOVINE $\beta$-CASEIN.

7

\begin{tabular}{llll}
\hline & \multicolumn{2}{c}{$\mathbf{A}^{a}$} \\
\cline { 2 - 4 } Bioactivity & $\begin{array}{l}\text { Large } \\
\text { subunit }\end{array}$ & $\begin{array}{l}\text { Small } \\
\text { subunit }\end{array}$ & $\begin{array}{l}\text { Bovine } \\
\boldsymbol{\beta} \text {-Casein }\end{array}$ \\
\hline ACE inhibitor & 0.4788 & 0.4472 & 0.6555 \\
Anorectic & $\mathrm{n} / \mathrm{a}$ & $\mathrm{n} / \mathrm{a}$ & 0.0048 \\
Activating ubiquitin-mediated proteolysis & 0.0191 & 0.0163 & $\mathrm{n} / \mathrm{a}$ \\
Antiamnestic & 0.0085 & 0.0081 & 0.0478 \\
Anticancer & $\mathrm{n} / \mathrm{a}$ & $\mathrm{n} / \mathrm{a}$ & 0.0191 \\
Antioxidative & 0.0742 & 0.0813 & 0.0909 \\
Antithrombotic & 0.0085 & 0.0081 & 0.0287 \\
Bacterial permease ligand & $\mathrm{n} / \mathrm{a}$ & 0.0244 & 0.0048 \\
Chemotactic & $\mathrm{n} / \mathrm{a}$ & $\mathrm{n} / \mathrm{a}$ & 0.0048 \\
Dipeptidyl peptidase IV inhibitor & 0.6441 & 0.6911 & 0.8182 \\
Hypotensive & 0.0064 & 0.0325 & 0.0048 \\
Immunomodulating & 0.0042 & $\mathrm{n} / \mathrm{a}$ & 0.0191 \\
Immunostimulating & $\mathrm{n} / \mathrm{a}$ & $\mathrm{n} / \mathrm{a}$ & 0.0048 \\
Inhibitor & 0.0064 & 0.0325 & 0.0048 \\
Neuropeptide & 0.0042 & 0.0163 & $\mathrm{n} / \mathrm{a}$ \\
Opioid & $\mathrm{n} / \mathrm{a}$ & 0.0081 & 0.0144 \\
Regulating & 0.0148 & 0.0081 & 0.0287 \\
Stimulating & 0.0339 & 0.0325 & 0.0718 \\
\hline A & & &
\end{tabular}

${ }^{a} \mathrm{~A}=\mathrm{a} / \mathrm{N}$, where $\mathrm{A}$ is the frequency of bioactive fragments occurrence in protein sequence, $\mathrm{a}$ is the number of fragments with given activity in the protein sequence, and $\mathrm{N}$ is the number of amino acid residues of the protein. The calculations were done using the BIOPEP software at http://www.uwm.edu.pl/biochemia/index.php/en/biopep 
TABLE 4. POTENTIAL RELEASE OF DIPEPTIDYL PEPTIDASE IV INHIBITING PEPTIDES FROM THE LARGE AND SMALL SUBUNITS OF ALFALFA RUBISCO

17 AFTER ENZYMATIC HYDROLYSIS.

18

\begin{tabular}{lllllll}
\hline & \multicolumn{2}{l}{ Large subunit $^{\boldsymbol{a}}$} & \multicolumn{2}{c}{ Small subunit $^{\boldsymbol{a}}$} & \multicolumn{2}{c}{ Bovine $\boldsymbol{\beta}$-Casein $^{\boldsymbol{a}}$} \\
\cline { 2 - 7 } & $\mathbf{A}_{\mathbf{E}}^{\boldsymbol{b}}$ & $\mathbf{W}^{\boldsymbol{c}}$ & $\mathbf{A}_{\mathbf{E}}$ & $\mathbf{W}$ & $\mathbf{A}_{\mathbf{E}}$ & $\mathbf{W}$ \\
\hline $\begin{array}{l}\text { Cysteine proteases } \\
\text { Bromelain }\end{array}$ & 0.0360 & 0.0559 & 0.0163 & 0.0236 & 0.0144 & 0.0176 \\
$\begin{array}{l}\text { Ficin } \\
\text { Papain }\end{array}$ & 0.0636 & 0.0987 & 0.0569 & 0.0823 & 0.0813 & 0.0994 \\
$\begin{array}{l}\text { Serine proteases } \\
\text { Chymotrypsin A }\end{array}$ & 0.0699 & 0.1085 & 0.0325 & 0.0470 & 0.0239 & 0.0292 \\
$\begin{array}{l}\text { Trypsin } \\
\text { Aspartate protease }\end{array}$ & 0.0191 & 0.0297 & 0.0407 & 0.0589 & 0.0335 & 0.0409 \\
$\begin{array}{l}\text { Pepsin } \\
\text { Metalloprotease }\end{array}$ & 0.0106 & 0.0165 & 0.0163 & 0.0236 & 0.0239 & 0.0292 \\
Thermolysin & 0.0614 & 0.0953 & 0.0244 & 0.0353 & 0.0526 & 0.0643 \\
\hline UniProtKB access & & 0.0081 & 0.0117 & 0.0048 & 0.0059 \\
\hline
\end{tabular}

${ }^{a}$ UniProtKB accession numbers $\underline{\mathrm{P} 04991}$ for alfalfa RuBisCO large subunit, $\underline{\mathrm{O} 65194}$ for alfalfa RuBisCO small subunit, and $\underline{\mathrm{P} 02666}$ for bovine $\beta$-casein.

${ }^{b} A_{E}=d / N$, where $A_{E}$ is the frequency of release of fragments with given activity by the selected enzyme, $\mathrm{d}$ is the number of peptides with given activity released by given enzyme, and $\mathrm{N}$ is the number of amino acid residues in the protein (Minkiewicz et al., 2008).

${ }^{c} \mathrm{~W}=\mathrm{A}_{\mathrm{E}} / \mathrm{A}$, where $\mathrm{W}$ is the relative frequency of release of fragments with given activity by selected enzyme, and $\mathrm{A}$ is the frequency of bioactive fragments occurrence in protein sequence (Minkiewicz et al., 2008). The calculations were done using the BIOPEP software at http://www.uwm.edu.pl/biochemia/index.php/en/biopep 


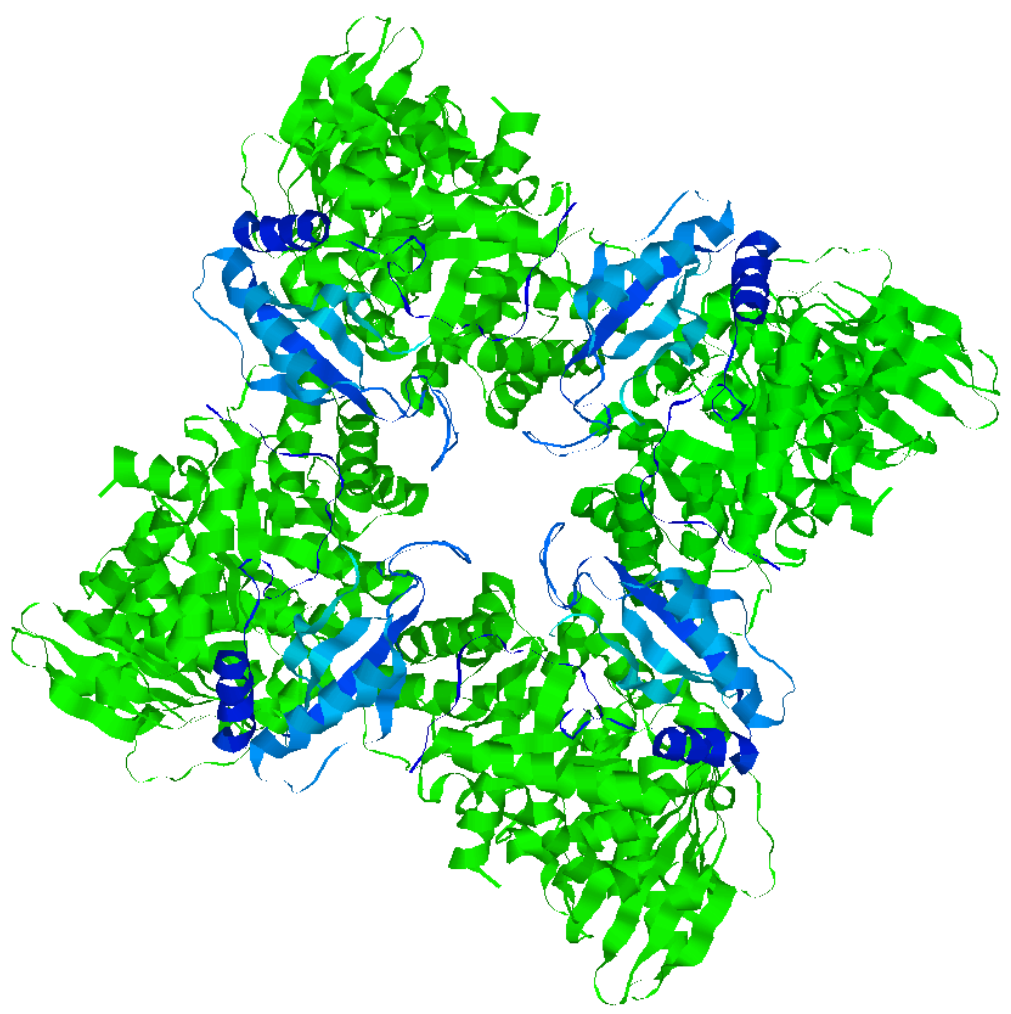

30

$31 \quad$ Fig. 1.

32

33

34

35

36

37

38

39

40

41

42

43

44 


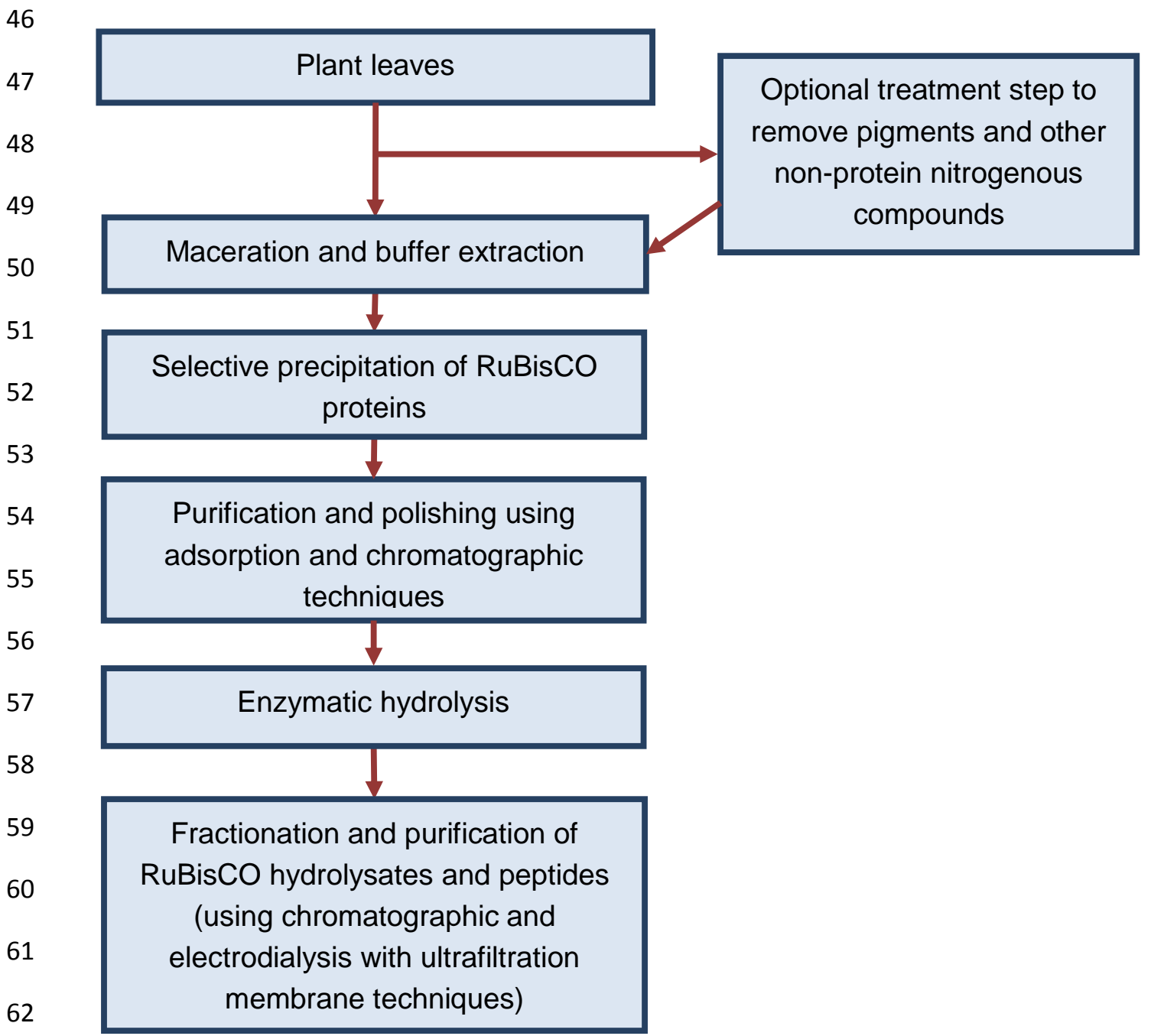

63

64 Fig. 2.

65 